OPEN ACCESS

Edited by:

Luciana Balboa,

Consejo Nacional de

Investigaciones Cientificas y

Técnicas (CONICET), Argentina

Reviewed by:

Mario M. D'Elios,

University of Florence, Italy

Beatrix Schumak,

University of Bonn, Germany

*Correspondence:

Pablo Iribarren

piribarr@fcq.unc.edu.ar

tThese authors have contributed equally to the present work.

Specialty section:

This article was submitted to Microbial Immunology,

a section of the journal

Frontiers in Immunology

Received: 15 August 2017 Accepted: 14 November 2017 Published: 04 December 2017

Citation:

Peralta Ramos JM, Bussi C, Gaviglio EA, Arroyo DS, Baez NS, Rodriguez-Galan MC and lribarren P (2017) Type / IFNs Are Required to Promote Central Nervous System Immune Surveillance through the

Recruitment of Inflammatory

Monocytes upon Systemic Inflammation.

Front. Immunol. 8:1666 doi: 10.3389/fimmu.2017.01666

\section{Type I IFNs Are Required to Promote Central Nervous System Immune Surveillance through the Recruitment of Inflammatory Monocytes upon Systemic Inflammation}

\author{
Javier María Peralta Ramos, Claudio Bussit, Emilia Andrea Gaviglio', \\ Daniela Soledad Arroyo, Natalia Soledad Baez, Maria Cecilia Rodriguez-Galan \\ and Pablo Iribarren*
}

Centro de Investigación en Bioquímica Clínica e Inmunología (CIBICI-CONICET), Departamento de Bioquímica Clínica,
Facultad de Ciencias Químicas, Universidad Nacional de Córdoba, Córdoba, Argentina

Brain-resident microglia and peripheral migratory leukocytes play essential roles in shaping the immune response in the central nervous system. These cells activate and migrate in response to chemokines produced during active immune responses and may contribute to the progression of neuroinflammation. Herein, we addressed the participation of type I-II interferons in the response displayed by microglia and inflammatory monocytes to comprehend the contribution of these cytokines in the establishment and development of a neuroinflammatory process. Following systemic lipopolysaccharide (LPS) challenge, we found glial reactivity and an active recruitment of CD45 hi leukocytes close to CD31+ vascular endothelial cells in circumventricular organs. Isolated CD11 b+

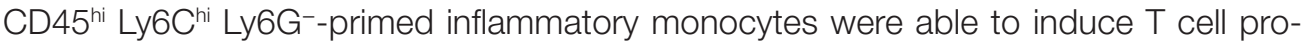
liferation, unlike CD11 b ${ }^{+}$CD45 $5^{\text {lo }}$ microglia. Moreover, ex vivo re-stimulation with LPS exhibited an enhancement of $\mathrm{T}$ cell proliferative response promoted by inflammatory monocytes. These myeloid cells also proved to be recruited in a type I interferon-dependent fashion as opposed to neutrophils, unveiling a role of these cytokines in their trafficking. Together, our results compares the phenotypic and functional features between tissue-resident vs peripheral recruited cells in an inflamed microenvironment, identifying inflammatory monocytes as key sentinels in a LPS-induced murine model of neuroinflammation.

Keywords: microglia, inflammatory monocytes, inflammation, lipopolysaccharide, interferons

\section{INTRODUCTION}

Immunological surveillance of the central nervous system (CNS) is dynamic, specific, and tightly regulated. During neuroinflammation, the blood-brain barrier (BBB) might get disrupted, enabling peripheral immune cells to gain access to the brain parenchyma. Brain-resident microglia encounter myeloid immune cells that have been primed in the periphery, establishing an interplay that could lead to the development and worsening of this inflammatory process with a detrimental outcome $(1,2)$. 
Systemic injection of the endotoxin lipopolysaccharide (LPS), a cell wall component of Gram-negative bacteria and a canonical ligand for toll-like receptor 4 (TLR4), has been widely used as an inflammatory model (3-14). These peripherally applied stimuli leads to a cytokine-storm that signals to the brain, inducing a decline in $\mathrm{BBB}$ integrity and triggering an immune response within it.

Tissue-resident microglia represent the first line of defense against invading pathogens and modulate neuroinflammation. Despite being extremely long-lived, microglia exhibit considerable self-renewal (15) and are highly active surveillants of the CNS under steady-state conditions (16). Peripheral bloodderived monocytes consist of two functional subsets, a patrolling $\mathrm{CX}_{3} \mathrm{CR} 1^{\text {hi }} \mathrm{CCR} 2^{-}$subset and an inflammatory $\mathrm{CX}_{3} \mathrm{CR} 1^{\text {lo }} \mathrm{CCR} 2^{+}$ subset (17) with the ability to migrate to inflamed tissues and differentiate into dendritic cells (18) or microglia under defined conditions $(19,20)$.

Current knowledge in neuroimmunology remains scarce. The recognition of a lymphatic drainage system of the CNS has drawn attention to the meninges and the choroid plexus, challenging the established basic assumptions of the CNS immune privilege (21, 22). In this regard, type I and II interferon (IFN-a/b and IFN-g) pathways have proved to be part of an elaborate cytokine network regulating the migration of immune cells through these CNS gateways (23), seemingly yielding opposite effects.

There is growing evidence that systemic inflammatory events can have devastating effects in the brain $(4,24,25)$ due to their impact in the progression of several CNS disorders $(11,26)$, such as autoimmune and neurodegenerative diseases in which leukocyte recruitment is a key feature. Understanding the impact of systemic inflammation in myeloid cell trafficking into the CNS and the underlying mechanisms involved in this process is determining.

In our study, we shed light on the differential roles of microglia and inflammatory monocytes $(27,28)$ and contributed to elucidate the participation of type I-II interferons during the immune response elicited by these tissue-resident versus peripheral recruited cells in a lipopolysaccharide (LPS)-induced murine model of neuroinflammation.

\section{MATERIALS AND METHODS}

\section{Animals and LPS Administration}

Wild-type (WT) C57BL/6 mice were originally obtained from School of Veterinary, National University of La Plata. IFN-g $^{-/-}$(B6.129S7-Ifngtm1Ts/J strain) mice were obtained from The Jackson Laboratory and IFNAR ${ }^{-/}$(Ifnar1tm1Ag strain) mice were kindly provided by Institut Pasteur. Between 8- and 12-week-old male mice were maintained in the specific pathogen-free barrier facilities at the School of Chemical Sciences animal facility, where all experiments were done in compliance with the procedures outlined in the "Guide for the Care and Use of Laboratory Animals" (NIH Publication No. 86-23, 1985). The experimental protocols were approved by the Institutional Animal Care and Use Committee (IACUC). Our animal facility obtained $\mathrm{NIH}$ animal welfare assurance (No. A5802-01, OLAW, NIH, US).
Lipopolysaccharide from Escherichia coli 055:B5 (purified by gel-filtration chromatography) was purchased from SigmaAldrich and freshly dissolved in sterile saline prior to intraperitoneal (i.p.) injection. Mice were treated with either vehicle or $40 \mu \mathrm{g}$ of LPS $(1,6 \mathrm{mg} / \mathrm{kg})$ for four consecutive days to induce neuroinflammation, following an injection scheme modified from Cardona et al. (5).

\section{Isolation of Immune Cells from Mice Brains}

Twelve hours post the last i.p. injection, mice were weighed and deeply anesthetized with a ketamine/xylazine cocktail according to their weight. Immune cells were isolated from whole brain homogenates as follows. Briefly, mice were transcardially perfused with ice-cold PBS (Gibco), and brains were collected in DMEM (Gibco) supplemented with sodium pyruvate (Gibco) and a penicillin, streptomycin, and glutamine cocktail (Gibco), gently disaggregated mechanically and resuspended in PBS containing $3 \mathrm{mg} / \mathrm{mL}$ collagenase D (Roche Diagnostics) plus $10 \mu \mathrm{g} / \mathrm{mL}$ DNAse (Sigma-Aldrich) for an enzymatically homogenization. After this incubation, brain homogenates were filtered in $40-\mu \mathrm{m}$ pore size cell strainers (BD Biosciences), centrifuged $8 \mathrm{~min}$ at $1,800 \mathrm{rpm}$, washed with PBS, and resuspended in $6 \mathrm{~mL}$ of $38 \%$ isotonic Percoll ${ }^{\circledR}$ (GE Healthcare) before a 25 -min centrifugation at $800 \mathrm{~g}$ without neither acceleration nor brake. Myelin and debris were discarded. Cell pellets containing total brain immune cells were collected, washed with DMEM supplemented with $10 \%$ fetal bovine serum (Gibco), and cell viability was determined by trypan blue exclusion using a Neubauer's chamber. Finally, cells were labeled for subsequent flow cytometric analysis or cell sorting.

\section{Flow Cytometric Analysis and Cell Sorting}

Surface staining of single-cell suspension of isolated brain immune cells was performed using standard protocols and analyzed on a FACS Canto II (BD Biosciences) or sorted on a FACS Aria III (BD Biosciences). Sort gates were defined based on the expression of CD11b, CD45, Ly6C, and Ly6G as follows: microglial cells, $\mathrm{CD}_{11 b^{+}} \mathrm{CD}_{45} 5^{\text {lo}}$; neutrophils, CD11b ${ }^{+} \mathrm{CD} 45^{\mathrm{hi}} \mathrm{Ly} 6 \mathrm{C}^{+} \mathrm{Ly}^{+} \mathrm{G}^{+}$; inflammatory monocytes, CD $11 b^{+}$CD $45^{\text {hi }}$ Ly6C ${ }^{\text {hi }}$ Ly6G $^{-}$. Data analysis was conducted using FCS express (De Novo Software). The following antibodies were used in the procedure: monoclonal anti-mouse CD11b APC (BioLegend, clone M1/70), CD11b FITC (BD Pharmingen, clone M1/70), CD45 APC-Cy7 (BioLegend, clone 30-F11), CD11c PerCP (BD Pharmingen, clone N418), Ly6C PE-Cy7 (BD Pharmingen, clone AL-21), Ly6G PE (BD Pharmingen, clone 1A8), I-A/I-E Alexa Fluor 647 (BioLegend, clone M5/114.15.2), FceRI PE-Cy7 (eBioscience, clone MAR-1), CCR2 (Abcam, clone E68), or polyclonal anti-mouse $\mathrm{CX}_{3} \mathrm{CR} 1$ (Abcam) plus Alexa Fluor 488 (Molecular Probes) antibody or isotype control antibodies (BD Pharmingen, APC, clone R35-95; PerCP/PE, clone A95-1; PE-Cy7, clone G155-178). The assessment of intracellular expression of chemokine receptors was performed according to the Cytofix/Cytoperm ${ }^{\mathrm{TM}}$ fixation/ permeabilization solution kit (BD Biosciences) manufacturer's instructions. Briefly, cells were surface-labeled as mentioned 
above. Then, samples were fixed and permeabilized for $20 \mathrm{~min}$ at $4^{\circ} \mathrm{C}$ with Fixation/Permeabilization solution and washed with BD Perm/Wash buffer ${ }^{\mathrm{TM}}$. Next, cells were incubated with BD Perm/Wash buffer ${ }^{\mathrm{TM}}$ containing monoclonal anti-mouse CCR2 (Abcam, clone E68) or polyclonal anti-mouse $\mathrm{CX}_{3} \mathrm{CR} 1$ (Abcam). Finally, samples were washed with BD Perm/Wash buffer ${ }^{\mathrm{TM}}$ and resuspended in the same buffer containing Alexa Fluor 488 antibody (Molecular Probes).

\section{Ex Vivo Suppression Assays}

Microglial cells or inflammatory monocytes isolated from endotoxemic mice, stimulated or not with a LPS $(100 \mathrm{ng} / \mathrm{mL})$ plus interferon gamma (IFN-g, $20 \mathrm{ng} / \mathrm{mL}$ ) (Peprotech) cocktail were cocultured with splenocytes derived from naïve control mice and previously stained with CFSE $(4 \mu \mathrm{M})$ (Molecular Probes), at a $1: 1$ ratio $\left(1 \times 10^{5} \mathrm{cell} / \mathrm{mL}\right)$. For mitogenic-induced cell proliferation, cocultures were maintained for $72 \mathrm{~h}$ in round-bottom 96-well plates in the presence or absence of Concanavalin A (Con A, $5 \mu \mathrm{g} / \mathrm{mL}$ ) (Sigma-Aldrich) in RPMI (Gibco) supplemented with $10 \%$ fetal bovine serum (Gibco). Cells were then harvested and stained with CD4 APC (BD Pharmingen, clone RM4-5) and CD8 PE (BD Pharmingen, clone 53-6.7) and analyzed as mentioned above.

\section{Reverse Transcription of mRNA and Quantification by Real-time PCR}

Brain homogenates or isolated cells were incubated with TRIzol ${ }^{\circledR}$ (Invitrogen), then RNA was extracted according to the manufacturer's instructions and stored at $-80^{\circ} \mathrm{C}$. Total RNA was quantified using a Synergy HT spectrophotometer (BioTek) and $1 \mu \mathrm{g}$ was treated with DNAse (Sigma-Aldrich) and reverse-transcribed using the High-Capacity cDNA Reverse Transcription Kit (Applied Biosystems) and following the manufacturer's protocol. Real-time PCR was performed on a StepOnePlus ${ }^{\mathrm{TM}}$ real-time PCR system (Applied Biosystems) using SYBR ${ }^{\circledR}$ Green real-time PCR master mix (Applied Biosystems), and relative quantification (RQ) was calculated by using StepOne ${ }^{\mathrm{TM}}$ software V2.2.2, based on the equation $R Q=2^{-\Delta \Delta C t}$, where $\mathrm{Ct}$ is the threshold cycle to detect fluorescence. Ct data were normalized to the internal standard HPRT1. Primer sequences were as follows: CCL2, sense: CCC ACT CAC CTG CTA CT, anti-sense: TCT GGA CCC ATT CCT TCT TG; CCR2, sense: GTG TGA TTG ACA AGC ACT TAG ACC, anti-sense: GGA GAG ATA CCT TCG GAA CTT CTC; $\mathrm{CX}_{3} \mathrm{CL} 1$, sense: CGA AAT GCG AAA TCA TGT GCG AC, anti-sense: GAC TCC TGG TTT AGC TGA TAG CG; CX $_{3}$ CR1: GGA CTC ACT ACC TCA GCC, anti-sense: TCC GGT TGT TCA TGG AGT TGG; CXCL1, sense: CAC CTC AAG AAC ATC CAG AGC, anti-sense: GGT CGC GAG GCT TGC CTT GA; CXCR2, sense: CTG GCA TGC CCT CTA TTC TGC, anti-sense: GCT GGT CAT CTT ATA CAA CGG G; IFN-b, sense: TTA CAC TGC CTT TGC CAT CC, anti-sense: ACT GTC TGC TGG AGT TCA T; IFNAR, sense: CGA GGC GAA GTG GTT AAA A, antisense: ACG GAT CAA CCT CAT TCC AC; HPRT1, sense: TCA GTC AAC GGG GGA CAT AAA, anti-sense: GGG GCT GTA CTG CTT AAC CAG.

\section{H\&E Staining and Immunofluorescence}

Twelve hours post the last i.p. injection, mice were weighed and deeply anesthetized with a ketamine/xylazine cocktail according to their weight. Animals were transcardially perfused once with ice-cold PBS (Gibco) and then with $4 \%$ paraformaldehyde. Brains were collected in $4 \%$ paraformaldehyde for an additional $24 \mathrm{~h}$ post-fixation and incubated in $20 \%$ sucrose for $24 \mathrm{~h}$ more.

For H\&E staining, brains were embedded in paraffin, cut into $10 \mu \mathrm{m}$ sections of thickness using a Shandon Cryotome E cryostat (Thermo Scientific), and mounted on Starfrost ${ }^{\circledR}$ adhesive slides (Knittel Glass). Then, sections were immersed in hematoxylin and rinsed in distilled water. Next, slides were immersed in eosin and rinsed three times with 95\% isopropilic alcohol. Following that, sections were quickly rinsed in a combined solution of xylene and ethanol and twice in xylene. Finally, slides were mounted with a drop of Canada balsam and analyzed under an Eclipse TE 2000-Ulight microscope (Nikon) with an ACT-2U digital camera (Nikon) attached to it to capture the images.

For immunofluorescence, brains were embedded in Tissue$\mathrm{Tek}^{\circledR}$ optimal cutting temperature compound (Sakura), cut into $10 \mu \mathrm{m}$ sections of thickness using a Shandon Cryotome E cryostat (Thermo Scientific), and mounted on Starfrost ${ }^{\circledR}$ adhesive slides (Knittel Glass). Sections were rehydrated with blocking buffer (10\% BSA, $0.3 \%$ Triton in TBS), rinsed with TBS (Gibco), and incubated overnight at $4^{\circ} \mathrm{C}$ with the corresponding dilutions of the antibodies CD45 (BioLegend, clone 30-F11), CD31 (Santa Cruz, clone M-20), or glial fibrillary acidic protein (Abcam, clone GF5) in blocking buffer. After several rinses, sections were incubated with Alexa Fluor 488 (Molecular Probes), Alexa Fluor 546 (Molecular Probes), or Alexa Fluor 633 (Molecular Probes) antibodies and counterstained with DAPI. Slides were analyzed under a FV1000 laser scanning confocal fluorescence microscope (Olympus).

\section{Statistical Analysis}

Results are expressed as mean \pm SEM. Data distribution was assumed to be normal, but this was not formally tested for all experiments. All statistical analyses were performed using Prism ${ }^{\circledR}$ 7.0 (GraphPad software). Means between two groups were compared with unpaired $t$-test. Means between three or more groups were compared with two-way analysis of variance followed by a Tuckey's post hoc test. Statistical significance levels were set as follows: ${ }^{*}$ if $p<0.05,{ }^{* *}$ if $p<0.01$, and ${ }^{* *}$ if $p<0.001$.

\section{RESULTS}

\section{Systemic LPS Challenge Induces Glial Activation and Recruitment of Peripheral CD11b $^{+}$CD45 $^{\text {hi }}$ Ly6C $^{\text {hi }}$ Ly6G- Cells into the CNS}

To assess neuroinflammation and to establish the cellular players involved in this process after a systemic LPS challenge, we evaluated glial activation and the recruitment of peripheral 
immune cells to the CNS through a flow cytometry multiparametric gating analysis strategy (Figure S1 in Supplementary Material).

For this purpose, we took advantage of the differential expression of the myeloid surface antigen CD11b and the pan-leukocyte marker CD45 in tissue-resident microglial cells (CD11b ${ }^{+}$CD $\left.45^{\text {lo }}\right)$ and peripheral recruited immune cells $\left(\mathrm{CD} 11 \mathrm{~b}^{+/-} \mathrm{CD} 45^{\mathrm{hi}}\right)$ (Figures 1A-C). Following LPS stimulation and based on these selection criteria, we found no changes in the absolute number but a decrease in the frequency of microglial cells due to the overwhelming recruitment of peripheral leukocytes. This effect upon LPS injection was accompanied by a marked weight loss, probably due to the development of sickness behavior (Figure 1D). To characterize the phenotypic features of the leukocyte trafficking to the CNS, we identified neutrophils $\left(\mathrm{CD} 11 \mathrm{~b}^{+} \mathrm{CD} 45^{\text {hi }} \mathrm{Ly} \mathrm{C}^{+}\right.$ Ly $\left.6 \mathrm{G}^{+}\right)$and inflammatory monocytes $\left(\mathrm{CD} 11 \mathrm{~b}^{+} \mathrm{CD} 45^{\mathrm{hi}} \mathrm{Ly} \mathrm{C}^{\mathrm{hi}}\right.$ Ly $6 \mathrm{G}^{-}$) as the major population of CNS-associated phagocytes in LPS-treated mice (Figures 2A,B) among innate myeloid CD11 $\mathrm{b}^{+}$ CD45 hi leukocytes.

Correspondingly, we noticed an increase in the recruitment of professional antigen presenting dendritic cells $\left(\mathrm{CD} 11 \mathrm{~b}^{+}\right.$ $\mathrm{CD}^{2} 5^{\mathrm{hi}} \mathrm{CD}_{11 \mathrm{c}^{+}} \mathrm{Ly}^{-} \mathrm{C}^{-} \mathrm{Ly}_{6 \mathrm{G}}{ }^{-}$) and of a distinctive subset, derived from monocytes that differentiate in situ under inflammatory circumstances, termed inflammatory dendritic cells $\left(\mathrm{CD} 11 \mathrm{~b}^{+} \mathrm{CD}^{\mathrm{hi}} \mathrm{CD}^{\mathrm{hi}} \mathrm{c}^{+} \mathrm{Ly}^{+} \mathrm{C}^{+} \mathrm{FceRI} \mathrm{I}^{+}\right.$) (Figures 2A,B). Furthermore, we found $\mathrm{CD} 11 \mathrm{~b}^{-} \mathrm{CD} 45^{\mathrm{hi}} \mathrm{T}\left(\mathrm{Ly} 6 \mathrm{C}^{+}\right)$and B-like $\left(\right.$ Ly6C $C^{-}$) cells (Figures 2A,B). Our results clearly show that an inflammogen, such as LPS, promotes the redistribution of the
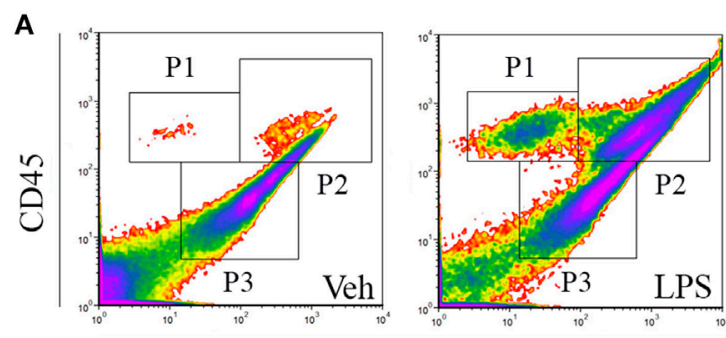

P1: Non-myeloid leukocytes (CD11b- CD45 $5^{\text {hi }}$ )

P2: Myeloid leukocytes (CD11 b ${ }^{+}$CD $\left.45^{\text {hi }}\right)$

P3: $\mathrm{Mi}\left(\mathrm{CD} 11 \mathrm{~b}^{+} \mathrm{CD} 45^{\mathrm{lo}}\right)$

CDllb

B

$\mathrm{CD} 11 \mathrm{~b}^{+} \mathrm{CD} 45^{\mathrm{lo}}$
C $\underset{\mathrm{CD} 11 \mathrm{~b}^{+} \mathrm{CD} 45^{10}}{\mathrm{Mi}}$

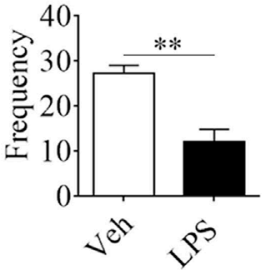

\section{Recruited leukocytes $\mathrm{CD} 11 \mathrm{~b}^{+/-} \mathrm{CD} 45^{\text {hi }}$}
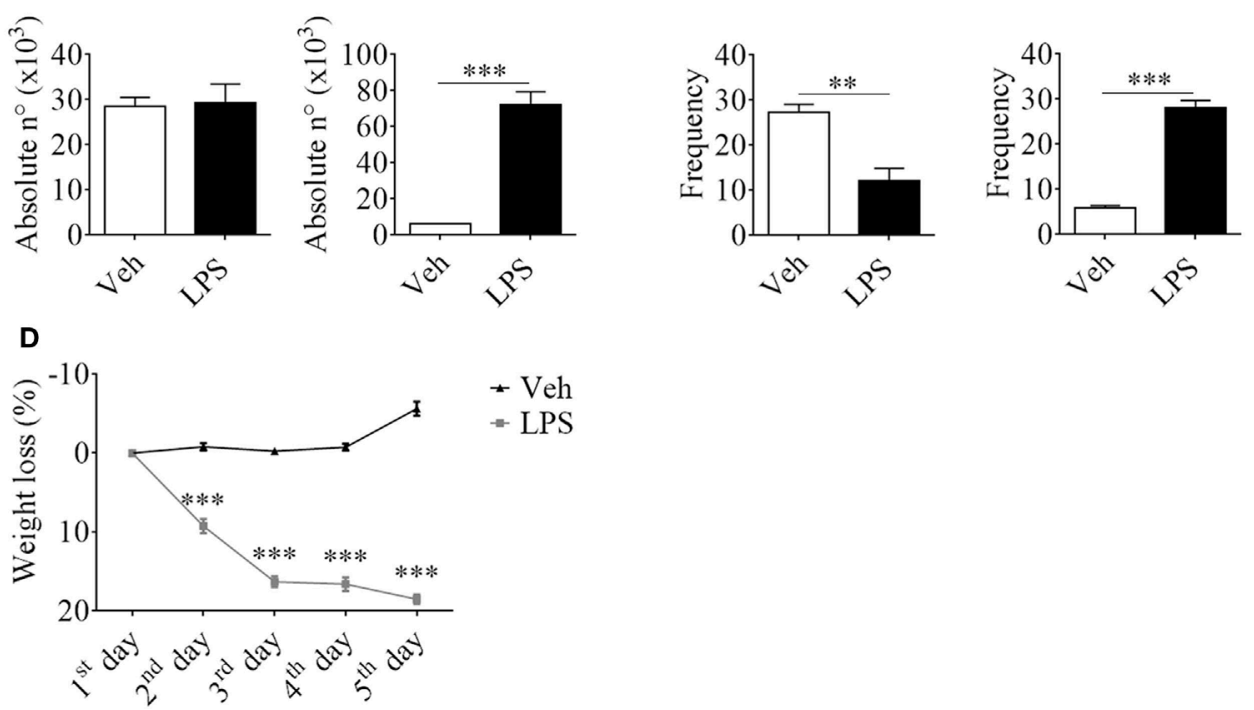

FIGURE 1 | Lipopolysaccharide (LPS) stimulation induces the recruitment of peripheral CD11 ${ }^{+/-}$CD45i cells to the central nervous system. Mice were treated i.p. with either vehicle or $40 \mu \mathrm{g}$ of LPS $(1,6 \mathrm{mg} / \mathrm{kg})$ for four consecutive days to induce neuroinflammation. Twelve hours post the last injection, mice were euthanized and immune cells were isolated from whole brain homogenates and labeled for subsequent flow cytometric analysis. (A) Representative CD45 vs CD11b flow cytometry density-plots illustrating the gating analysis strategy employed. P1: CD11 b- CD45 hi lymphoid recruited leukocytes; P2: CD11 b+ CD45 hi myeloid recruited leukocytes; P3: CD11 b+ CD45 microglial cells. (B) Absolute number and (C) frequency of CD11b+ CD45 ${ }^{10}$ microglial cells, CD11b ${ }^{+/-}$CD45 hi recruited leukocytes,

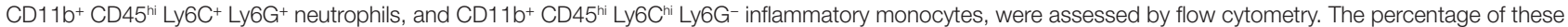
two last populations corresponding when gated in CD11 b+CD45 $\mathrm{b}^{\mathrm{hi}}$. Results are representative of at least three independent experiments $(n=3-4$ animals per group). (D) Mice weight loss following the i.p. administration scheme with vehicle or 40 $\mu \mathrm{g}$ of LPS (1.6 mg/kg) for four consecutive days to induce neuroinflammation. Results are representative of at least three independent experiments $(n=3-20$ animals per group). Data are expressed as mean \pm SEM. Mi, microglial cells; PMN, neutrophils; Inf Mo, inflammatory monocytes. 


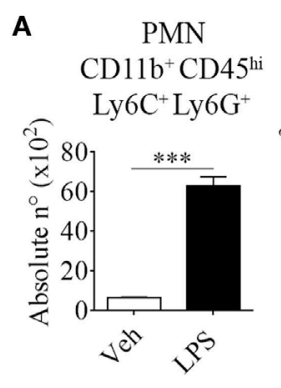

B

\section{PMN
$\mathrm{CD}_{11 b^{+}} \mathrm{CD} 45^{\mathrm{h}}$ Ly $6 \mathrm{C}^{+} \mathrm{Ly}_{6 \mathrm{G}^{+}}$}
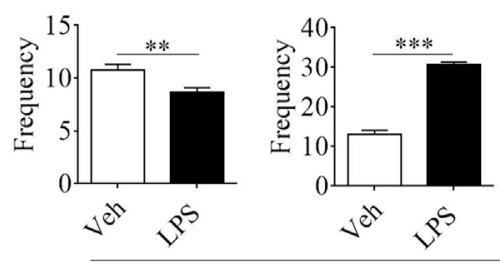

Inf Mo

$\mathrm{CD} 11 \mathrm{~b}^{+} \mathrm{CD} 45^{\mathrm{hi}}$

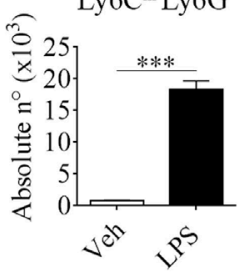

Inf Mo $\mathrm{CD}_{11 b^{+} \mathrm{CD} 45^{\mathrm{hi}}}$ Ly6C ${ }^{\text {hi }}$ Ly6 G

Gated in CD1 $1 b^{+}$CD45 ${ }^{\text {hi }}$ recruited cells
DCs

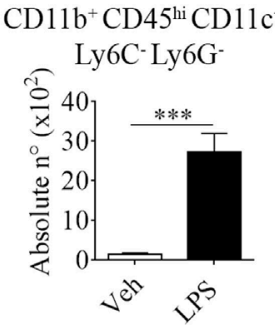

DCs

$\mathrm{CD} 11 \mathrm{~b}^{+} \mathrm{CD} 45^{\text {hi }} \mathrm{CD} 11 \mathrm{c}^{+}$ Ly6C- $\mathrm{Ly}^{6} \mathrm{G}^{-}$
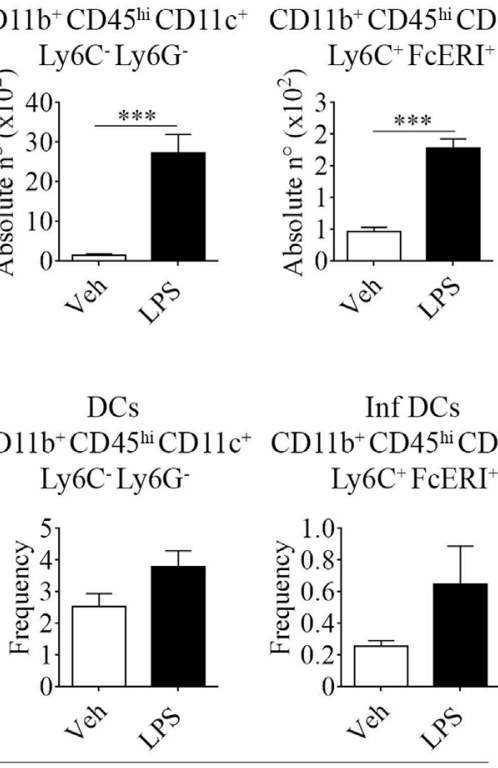

Inf DCs

CD $11 b^{+}$CD $45^{\text {hi }} \mathrm{CD} 11 \mathrm{c}^{+}$

Ly $6 \mathrm{C}^{+} \mathrm{FcERI}^{+}$

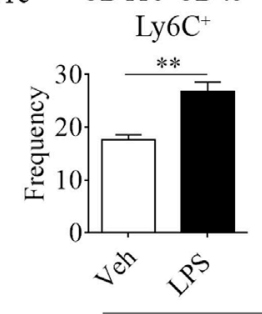

Gated in CD11b CD45 ${ }^{\text {hi }}$ recruited cells

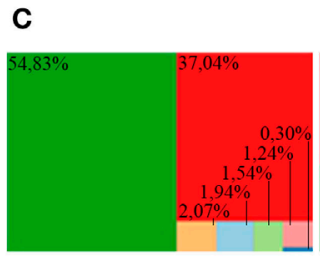

Veh

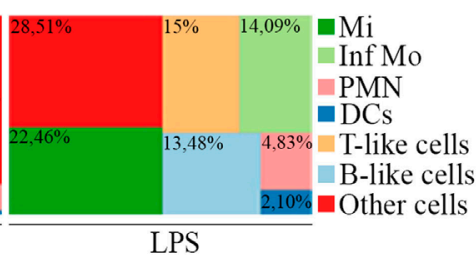

FIGURE 2 | Phenotypic features of immune cells involved in neuroinflammation in the brain from endotoxemic mice. Mice were treated i.p. with either vehicle or $40 \mu \mathrm{g}$ of lipopolysaccharide (LPS) $(1,6 \mathrm{mg} / \mathrm{kg})$ for four consecutive days to induce neuroinflammation. Twelve hours post the last injection, mice were euthanized and immune cells were isolated from whole brain homogenates and labeled for subsequent flow cytometric analysis. (A) Absolute number and (B) frequency of CD11 ${ }^{+}$

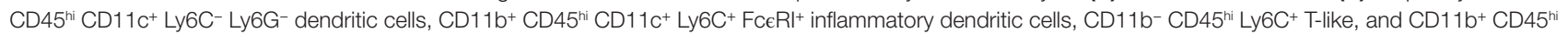
Ly6C- B-like lymphocytes, was assessed by flow cytometry. The percentages shown correspond to populations gated as CD11b+ CD45 hi . Results are representative of at least two independent experiments ( $n=3-4$ animals per group). (C) Representative hierarchical tree map comparing vehicle vs LPS frequency of resident and peripheral populations previously analyzed by flow cytometry. Results are representative of at least three independent experiments $(n=3-4$ animals per group). Data are expressed as mean \pm SEM. Mi, microglial cells; Inf Mo, inflammatory monocytes; PMN, neutrophils; DCs, dendritic cells; Inf DCs, inflammatory dendritic cells; other cells, neurons, astrocytes, oligodendrocytes.

frequencies of different populations of leukocytes recruited to the CNS when compared to those of neuronal or glial populations (Figure 2C).

Recent findings have revealed a role for circumventricular organs as gateways in the trafficking of peripheral leukocytes to the CNS. By virtue of this, we next assessed neuroinflammation and determined the location of the leukocytes recruited to the brain by both immunohistochemistry and immunofluorescence. Hematoxylin and eosin staining revealed recruitment of leukocytes in choroid plexus of endotoxemic mice (Figure 3A), confirming the involvement of this site in the immune surveillance of the brain. As mentioned above, when using confocal microscopy, we exploited both the morphology and the mild expression of the cluster of differentiation CD45 in star-shaped brain-resident microglial cells to distinguish them from rounded peripheral leukocytes bearing a high expression of this marker. Thus, systemic LPS induced microglial and astrocytic reactivity as shown by the shrinkage and thickening of glial processes and promoted the recruitment of inflammatory leukocytes, particularly close to vascular CD31-expressing endothelial cells in circumventricular organs (Figure 3B). Our results exhibited no infiltration of immune cells into the brain parenchyma but remain in the perivascular compartment, suggesting that at least under these circumstances, there may be no signals in the microenvironment to do so.

\section{LPS Stimulation Modulates CCR2 and $\mathrm{CX}_{3}$ CR1 Expression in Tissue-Resident

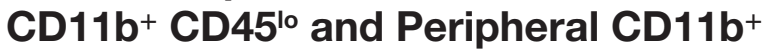 CD45 ${ }^{\text {hi }}$ Ly6C $^{\text {hi }}$ Ly6G- Cells}

Chemokines and their receptors are active players inducing the access of myeloid cells to the CNS. To better understand microglial activation and the selective migration of inflammatory 


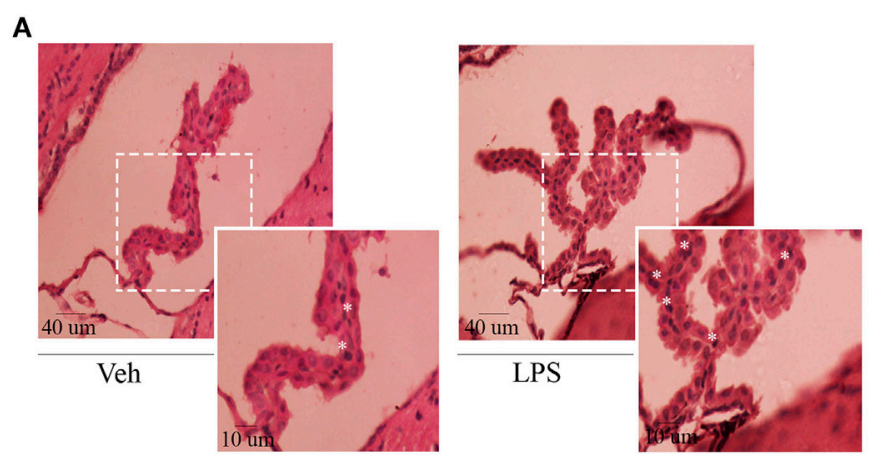

B
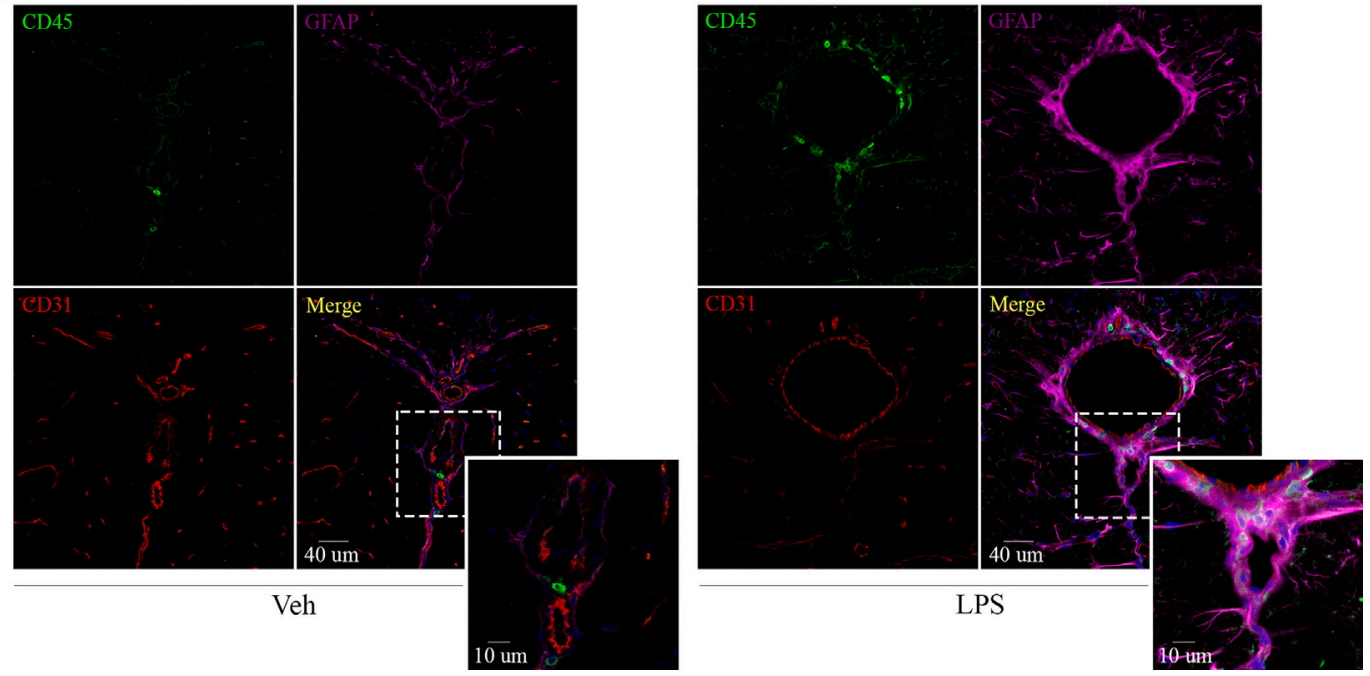

FIGURE 3 | Lipopolysaccharide (LPS) challenge induces glial activation and recruitment of leukocytes to CVOs. Mice were treated i.p. with either vehicle or 40 Mg of LPS (1,6 mg/kg) for four consecutive days to induce neuroinflammation. Twelve hours post the last injection, mice were euthanized and brains collected. (A) H\&E micrographs of the choroid plexus. Scale bars, $40 \mu \mathrm{m}$ (main panels), $13 \mu \mathrm{m}$ (inset). The asterisks denote recruited leukocytes. Results are representative of at least two independent experiments ( $n=3-4$ animals per group). (B) Confocal micrographs of CVOs depicting cluster of differentiation (CD45)-low microglial cells and high recruited leukocytes (upper-left, green), glial fibrillary acidic protein-positive astrocytes (upper-right, false-colored magenta), and cluster of differentiation (CD31)positive endothelial cells (lower-left, red). DAPI counterstain (blue) shows nucleus. Scale bars, $40 \mu \mathrm{m}$ (main panels), $13 \mu \mathrm{m}$ (inset). Results are representative of at least three independent experiments ( $n=3-4$ animals per group).

monocytes following a LPS challenge, we next assessed the status of CCL2/CCR2 and $\mathrm{CX}_{3} \mathrm{CL} 1 / \mathrm{CX}_{3} \mathrm{CR} 1$ axes.

Systemic LPS conversely modulated these chemokine/receptor axes, as determined by an increase in CCL2 and CCR2 gene expression levels but a decrease in both $\mathrm{CX}_{3} \mathrm{CL} 1$ and $\mathrm{CX}_{3} \mathrm{CR} 1$ in total bulk brains from LPS-treated mice when compared to their vehicle-treated counterparts (Figure 4A). Subsequently, we performed surface and intracellular staining of chemokine receptors CCR2 and $\mathrm{CX}_{3} \mathrm{CR} 1$ in tissue-resident microglia and peripheral inflammatory monocytes to further characterize the response exerted by LPS in these populations. Thereby, we noticed an increase in the absolute number of CCR2 surface-bearing microglia (Figures 4B,C and Figure S2 in Supplementary Material) and $\mathrm{CX}_{3} \mathrm{CR}^{+}$inflammatory monocytes (Figures 4D,E and Figure S2 in Supplementary Material) after LPS systemic administration. These results imply a positive feedback between the unhindered recruitment of CCR2 $2^{+}$cells and the exacerbation of inflammation through the downregulation of inhibitory $\mathrm{CX}_{3} \mathrm{CL} 1$ and $\mathrm{CX}_{3} \mathrm{CR} 1$, as shown by quantitative real-time PCR. Likewise, flow cytometry assays showed that despite not always promoting the expression of either CCR2 or $\mathrm{CX}_{3} \mathrm{CR} 1$ in the surface of microglia and inflammatory monocytes, LPS upregulates the expression of both chemokine receptors intracellularly in these populations.

\section{Plasticity of LPS-Primed Inflammatory CD11b+ CD45 hi Ly6C ${ }^{\text {hi }}$ Ly6G- Cells in the Regulation of T Cell Proliferation}

To date, several studies have described invading blood-derived monocytes as highly mobile and inflammatory, whereas resident microglia have been characterized as active motile CNS myeloid cells that function as the first line of defense against invading pathogens. Therefore, we addressed the hypothesis that inflammatory monocytes and microglia could be playing different roles in neuroinflammation by either promoting or suppressing $\mathrm{T}$ cell proliferative response.

To tackle this issue, we performed a proliferation assay in which CNS isolated inflammatory monocytes or microglia were 


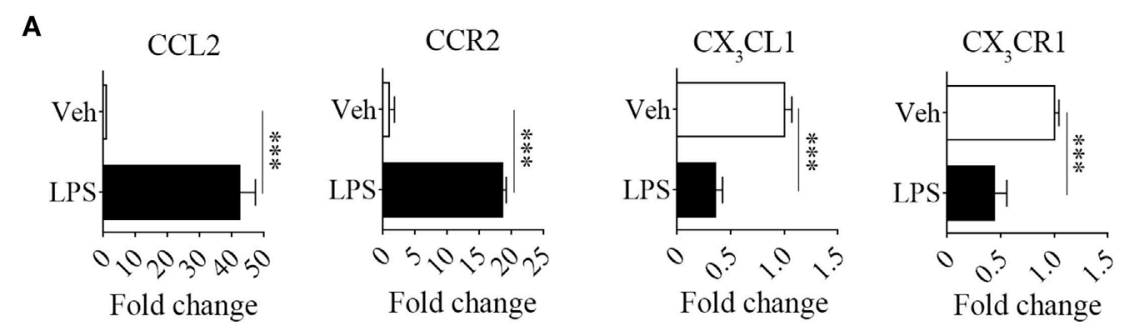

B

$\mathrm{Mi}$ $\mathrm{CD}_{11 \mathrm{~b}}{ }^{+} \mathrm{CD}^{2} 5^{\mathrm{lo}} \mathrm{CCR}^{+}$

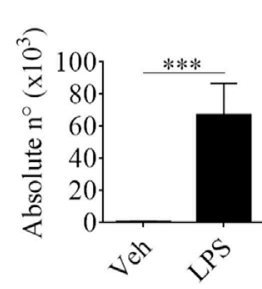

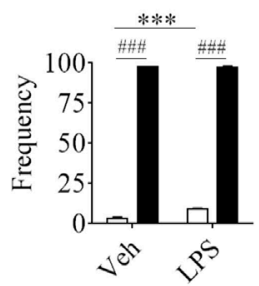

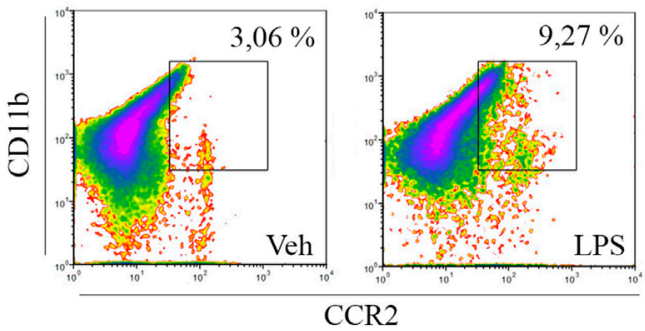

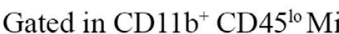

C

$\mathrm{Mi}$

$\mathrm{CD}_{11 \mathrm{~b}} \mathrm{CD}^{4} 5^{\mathrm{lo}} \mathrm{CX}_{3} \mathrm{CR}^{+}$
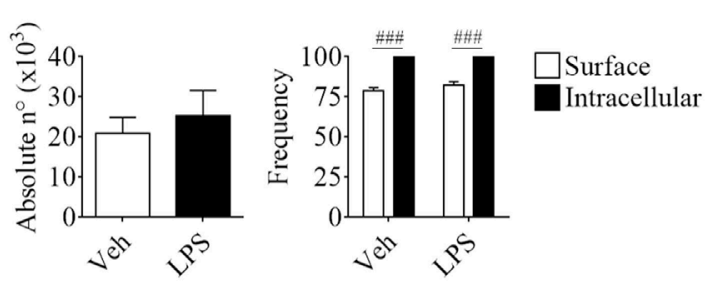

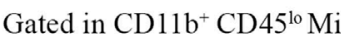

D

Inf Mo

$\mathrm{CD}_{11 b^{+} \mathrm{CD}^{\text {hii }} \text { Ly6C }^{\text {hi }} \text { Ly6G CCR2 }}{ }^{+}$

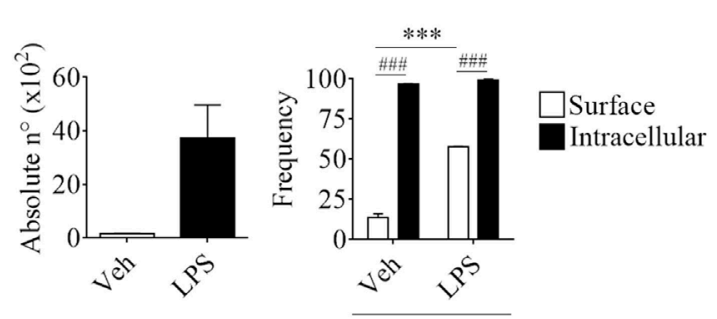

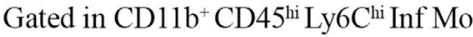

E Inf $\mathrm{Mo}$

$\mathrm{CD}_{11 \mathrm{~b}} \mathrm{CD}^{\mathrm{hi}} \mathrm{Ly}^{\mathrm{hi}} \mathrm{C}^{\mathrm{hi}} \mathrm{Ly} 6 \mathrm{G}^{-} \mathrm{CX}_{3} \mathrm{CR} 1^{+}$
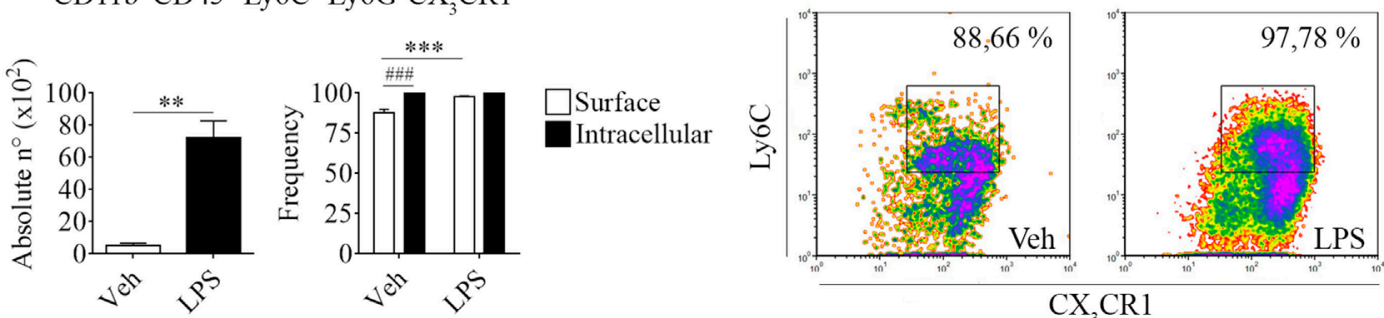

Gated in CD11 b ${ }^{+}$D $45^{\text {hi }}$ Ly6 ${ }^{\text {hi }}$ Inf Mo

FIGURE 4 | Continued 
FIGURE 4 | Continued

Increase of brain-resident CD11b+ CD45 ${ }^{10}$ and peripheral CD11 b+ CD45 hi Ly6C ${ }^{\text {hi }}$ Ly6G- cells bearing CCR2 and CX ${ }_{3}$ CR1 in lipopolysaccharide (LPS)-treated mice. Mice were treated i.p. with either vehicle or $40 \mu \mathrm{g}$ of LPS $(1,6 \mathrm{mg} / \mathrm{kg})$ for four consecutive days to induce neuroinflammation. Twelve hours post the last injection, mice were euthanized and RNA extracted from whole brain homogenates cells or immune cells isolated and labeled for subsequent flow cytometric analysis. (A) Gene expression analysis by real-time PCR of CCL2, $\mathrm{CX}_{3} \mathrm{CL} 1$ and $\mathrm{CCR} 2, \mathrm{CX}_{3} \mathrm{CR} 1$ in total bulk brain. Results are representative of at least two independent experiments ( $n=3$ animals per group). Relative quantification $(R Q)$ was calculated based on the equation $R Q=2^{-\Delta \Delta C t}$, where $C t$ is the threshold cycle to detect fluorescence. Ct data were normalized to the internal standard HPRT1. (B,D) Absolute number and $(\mathbf{C}, \mathbf{E})$ frequency of CD11 b+ CD45 microglial cells and CD11b+ CD45 ${ }^{\text {hi }}$ Ly6C ${ }^{\text {hi }}$ Ly6G ${ }^{-}$ inflammatory monocytes expressing CCR2 and $\mathrm{CX}_{3} \mathrm{CR} 1$, was assessed by flow cytometry. The percentage of these populations corresponding when gated in CD11 $\mathrm{b}^{+}$ $\mathrm{CD} 45^{\text {lo }}$ or CD11 b+ CD45 hi Ly6C ${ }^{\text {hi }}$, respectively. Representative density-plots illustrate the gating analysis strategy employed. Results are representative of two independent experiments ( $n=3-6$ animals per group). Data are expressed as mean \pm SEM. Mi, microglial cells; Inf Mo, inflammatory monocytes.
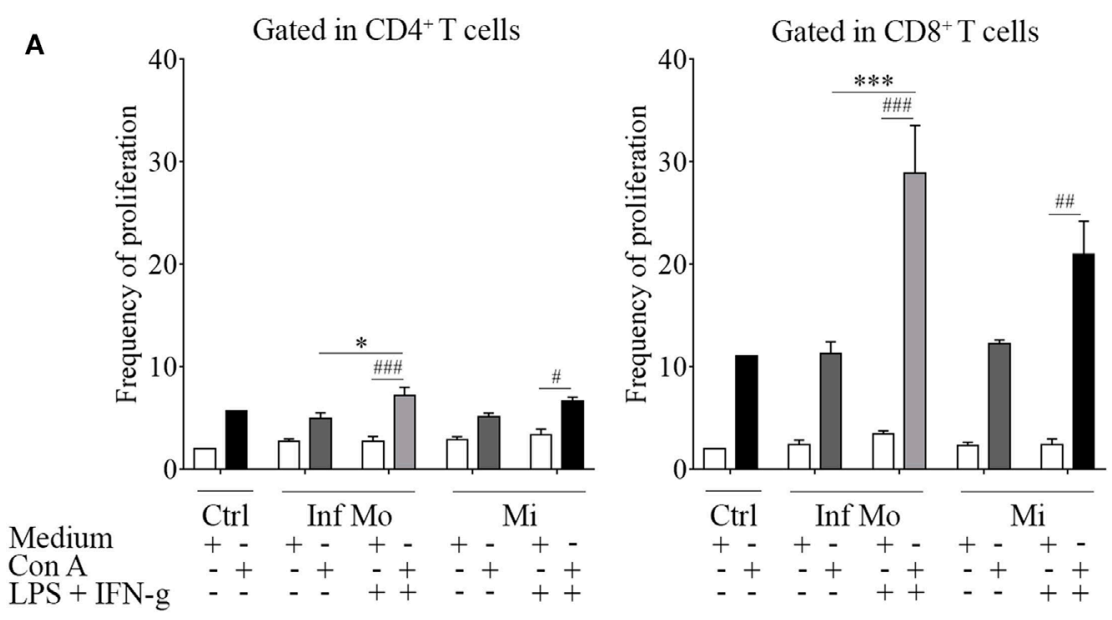

B

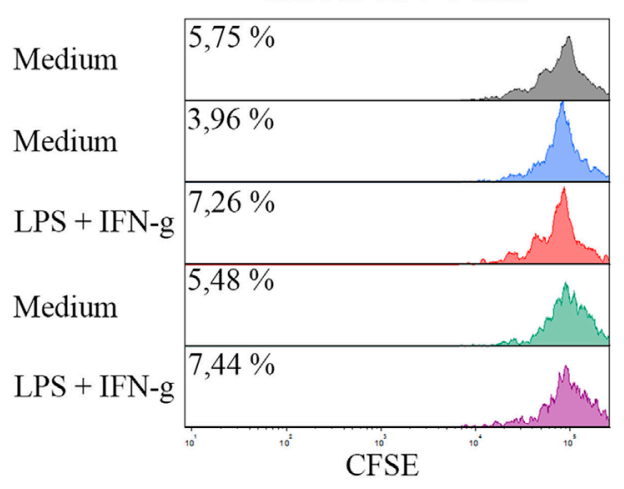

Gated in $\mathrm{CD}^{+} \mathrm{T}$ cells

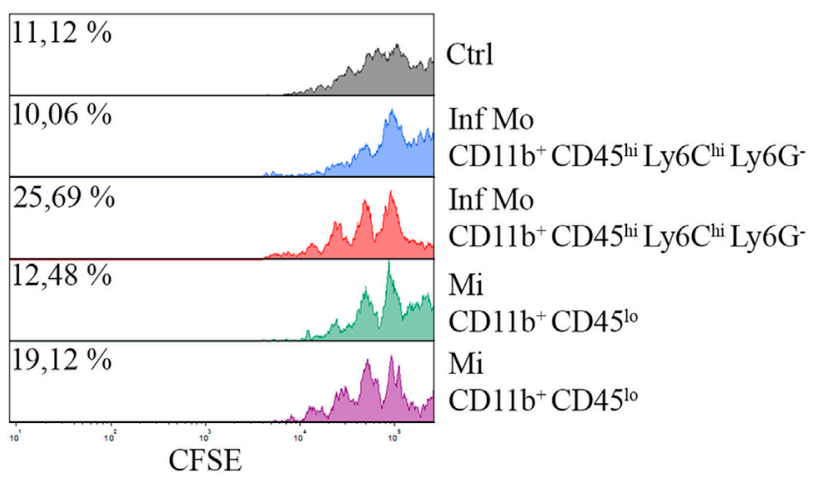

FIGURE 5 | Immune function of inflammatory CD11 b+ CD45 hi Ly6C ${ }^{\text {hi }}$ Ly6G ${ }^{-}$cells isolated after a systemic lipopolysaccharide (LPS) challenge. Mice were treated i.p. with either vehicle or $40 \mathrm{\mu g}$ of LPS $(1,6 \mathrm{mg} / \mathrm{kg})$ for four consecutive days to induce neuroinflammation. Twelve hours post the last injection, mice were euthanized and immune cells were isolated from whole brain homogenates and labeled for subsequent cell sorting. (A) In vivo LPS-primed CD11 L $^{+}$CD45 ${ }^{\text {hi }}$ Ly6C ${ }^{\text {hi }}$ Ly6Ginflammatory monocytes or CD11 b+ CD45 ${ }^{10}$ microglial cells isolated by cell sorting from a pool of mice brains were cocultured with CFSE (4 $\mu \mathrm{M}$ )-labeled naïve splenocytes at a $1: 1$ ratio $\left(1 \times 10^{5}\right.$ cell $\left./ \mathrm{mL}\right)$ in the presence or absence of concanavalin $\mathrm{A}$ (Con $\left.\mathrm{A}\right)(5 \mu \mathrm{g} / \mathrm{mL})$. Cells from endotoxemic mice were challenged or not ex vivo with LPS (100 ng/mL) plus IFN-g (20 ng/mL) cocktail prior to the coculture. T cell frequency of proliferation was examined after $72 \mathrm{~h}$ by CFSE dilution through flow cytometry. Results are representative of two independent experiments combined ( $n=17-20$ animals). (B) Representative stacked histograms depicting CFSE dilution. Data are expressed as mean \pm SEM. Ctrl, control; Inf Mo, inflammatory monocytes; Mi, microglial cells.

cocultured with naïve splenocytes in the presence or not of Con A. Interestingly, we found that LPS-primed inflammatory monocytes were able to induce $\mathrm{T}$ cell proliferation unlike microglia, in an increasing ratio-dependent manner (data not shown). To gain insight into this mechanism, we sought to test if peripheral isolated inflammatory monocytes and tissue-resident microglia might have functional plasticity by exposing or not these cells to a repeated ex vivo LPS challenge in addition with IFN-g as a combination of multiple activation signals prior to the coculture. Surprisingly, boosting of the cells showed an enhancement of $\mathrm{T}$ cell proliferation by inflammatory monocytes when compared to the single stimulation condition (Figure $\mathbf{5 A}$ ), as pictured by the representative CFSE dilution stacked histograms (Figure 5B). These results demonstrate monocytes and microglia are sensitive 
to pro-inflammatory re-stimulation and could differentially regulate $\mathrm{T}$ cell subsets multiplication, as suggested by $\mathrm{CD} 4^{+} \mathrm{T}$ cell weakened proliferative response in comparison with the $\mathrm{CD} 8^{+}$ $\mathrm{T}$ cell proliferation.

\section{Type I IFNs Are Required to Promote CD11b+ CD45 $^{\text {hi }}$ Ly6C $^{\text {hi }}$ Ly6G- Cell Recruitment to the CNS in Endotoxemic Mice}

Recent studies proposed IFNs as crucial mediators in brain function but many questions regarding the role of these molecules in the CNS remain unanswered yet. We appealed to our previously described flow cytometric analysis strategy to delve deeper in the understanding of these cytokines and evaluate whether if they could be participating in the modulation of neuroinflammation.

Following a systemic challenge with LPS, we did not find any variation in the absolute number of microglia but a decrease in the absolute number of recruited peripheral leukocytes in IFNs deficient mice strains compared to WT mice. This effect upon LPS injection in $\mathrm{KO}$ mice was accompanied by a reduced weight loss (Figure S3 in Supplementary Material), probably correlating with the observed decline in the immune cell recruitment to their CNS. Unexpectedly, we found LPS favored the recruitment of peripheral inflammatory monocytes rather than neutrophils in animals devoid of IFN-g. Moreover, inflammatory monocytes proved to be recruited to the CNS in a type I IFN-dependent fashion as opposed to neutrophils, as shown by the impairment in their recruitment in IFN-a/b receptor knockout (IFNAR ${ }^{-/-}$) brains (Figures 6A,B). In this sense, only LPS-challenged WT mice showed an increase in the recruitment of peripheral major histocompatibility class II (MHC II)-expressing inflammatory monocytes (Figure S4 in Supplementary Material). In order to clarify the underlying mechanism whereby peripheral inflammatory monocytes lacking the type I IFN receptor could mildly migrate to the CNS upon a systemic LPS administration, we then set out to identify the molecular mediator involved in this response. Thus, we separately isolated microglia, neutrophils and inflammatory monocytes and assessed the gene expression of several chemokine/receptor axes considered critical for the trafficking of these cells to the brain. As depicted by the representative gene array chart (Figure 6C), the increase in CCL2 gene expression levels in inflammatory monocytes suggest a redundant function for the recruitment of these cells. Indeed, the upregulation of $\mathrm{CX}_{3} \mathrm{CL} 1$ in neutrophils (Figures 6C,D) implies a crosstalk of this chemokine with type I IFNs as well as a requirement of both mediators for a proper immune cell entry to the CNS under inflammatory circumstances.

\section{DISCUSSION}

The results presented identify inflammatory monocytes as gatekeepers of CNS immune surveillance (29) upon a LPS peripheral challenge, as determined by the augmentation of their recruitment when compared to other immune cell populations. This is in agreement with Cazareth et al. (12), which shows an enhanced migration of inflammatory monocytes but neither trafficking of neutrophils nor T and B lymphocytes to the CNS by means of a similar flow cytometry approach, following a single and acute systemic administration of LPS. On the contrary, the finding of a consistent recruitment of these latter cells in our experimental settings demonstrates that the outcome of a proposed model varies depending on the dose and timing regime of LPS exposure. Several studies have described the design of LPS models to assess the implications of central or peripheral inflammation in the development of a less-common neurodegenerative condition such as prion disease $(4,11,26)$ or even to induce and mimic features of Alzheimer's (8) and Parkinson's disease (7) in naïve animals. Noteworthy, Ruiz-Valdepenas et al. (9) showed by intravital microscopy increased extravasation of dextran after a single moderate dose of LPS so it is certainly likely that in our neuroinflammation model this inflammogen would be gaining access, via BBB breakdown, to the parenchyma and activating directly to brain cells.

Similar to previous reports during pathogenic inflammation in experimental autoimmune encephalomyelitis $(30,31)$, we determined the presence of a peculiar subset of dendritic cells, termed inflammatory dendritic cells, in inflamed brains from endotoxemic mice. However, we particularly used FceRI to characterize these cells, to date probably the best phenotypic marker to distinguish inflammatory dendritic cells from other myeloid cells and avoid giving a mistaken identity (18). Inflammatory dendritic cells characterize for being absent from steady-state tissues and differentiate, as well as microglia $(19,20)$, from monocytes during inflammation. This would at least partially explain the presence of these cells, as revealed here, in spite of the fact that LPS could actually block the conversion of inflammatory monocytes into dendritic cells in vivo (3).

Recent findings support the idea of leukocyte trafficking under physiological and pathological circumstances along circumventricular organs that function as gateways in the CNS such as the choroid plexus (32), a unique neuroimmunological interface positioned to integrate the signals received from the parenchyma with signals coming from circulating immune cells (33-35). Accordingly, we found recruitment but no infiltration of leukocytes in this site along with microglial and astrocytic reactivity after systemic inflammation evoked by LPS as revealed by both the retraction of their processes and enlargement of their cell bodies, which are classic traits of glial activation $(5,16,36)$. It should be pointed out that our criteria for the use of the term infiltration was not that given by numerous works as a synonym of recruitment, but the phenomenon by which the cells can invade the parenchyma after their entry through the vessels. This is clearly not only a semantic problem, since the incorrect use of the term may lead to a misunderstanding of the results.

Myeloid cells recruitment to the CNS is a shared characteristic between several autoimmune and neurodegenerative diseases. Chemokine receptors CCR2 and $\mathrm{CX}_{3} \mathrm{CR} 1$ are both essential for myeloid cell trafficking and localization of migrating leukocytes $(17,37)$ to the perivascular space $(2,38,39)$. In this sense and consisting with previous observations (12), we found brain CCL2 production together with CCR2-expressing inflammatory monocytes would ease the selective migration of these cells to the CNS 
(20,40-42) following a LPS challenge. Moreover, downregulation of cerebral $\mathrm{CX}_{3} \mathrm{CL} 1$ and its receptor $\mathrm{CX}_{3} \mathrm{CR} 1$ would amplify this response, unleashing microglia pro-inflammatory role by removing the inhibition exerted by $\operatorname{CX}_{3} \operatorname{CL} 1(5,43,44)$.
Unlike microglia, LPS priming of isolated inflammatory monocytes led to an induction of $\mathrm{T}$ cell proliferative response (45). Despite ex vivo re-stimulation with LPS and IFN-g, a potent stimulus for the induction of $\mathrm{T}$ cell-suppressive nitric oxide
A

$\mathrm{Mi}$
$\mathrm{CD}_{11 \mathrm{~b}^{+} \mathrm{CD} 45^{\mathrm{lo}}}$

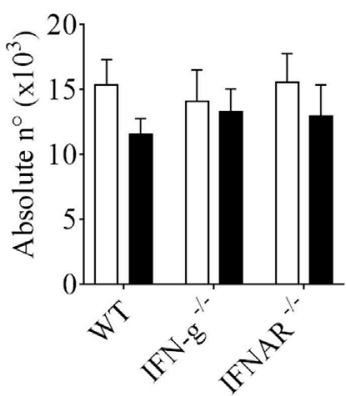

B

$\mathrm{Mi}$
$\mathrm{CD}_{11 \mathrm{~b}^{+} \mathrm{CD} 45^{\mathrm{lo}}}$
Recruited leukocytes

$\mathrm{CD} 11 b^{+/-} \mathrm{CD} 45^{\mathrm{hi}}$

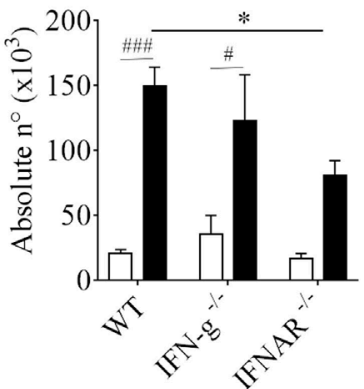

Recruited leukocytes

$\mathrm{CD}_{11} \mathrm{~b}^{+/} \mathrm{CD} 45^{\mathrm{hi}}$
PMN

CD $11 b^{+} \mathrm{CD} 45^{\text {hi }}$

$\mathrm{Ly}_{6 \mathrm{C}^{+}} \mathrm{Ly}_{6 \mathrm{G}^{+}}$
Inf Mo

$\mathrm{CD} 11 b^{+} \mathrm{CD} 45^{\mathrm{hi}}$

Ly6Chi Ly6G

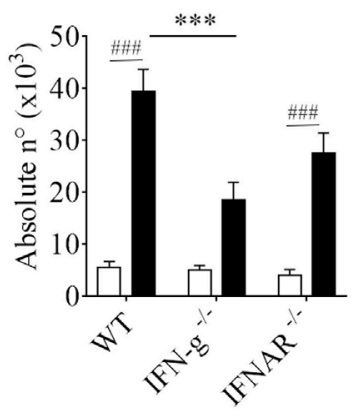

PMN

CD11b ${ }^{+}$CD45 $5^{\text {hi }}$

$\mathrm{Ly}_{6 \mathrm{C}^{+}} \mathrm{Ly}_{6 \mathrm{G}^{+}}$

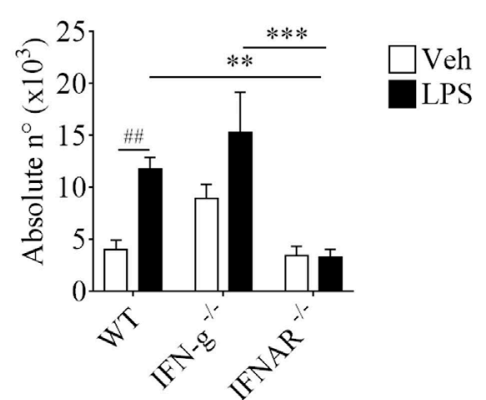

Inf Mo

$\mathrm{CD}_{11} \mathrm{~b}^{+} \mathrm{CD} 45^{\mathrm{hi}}$

Ly6Chi Ly6G-
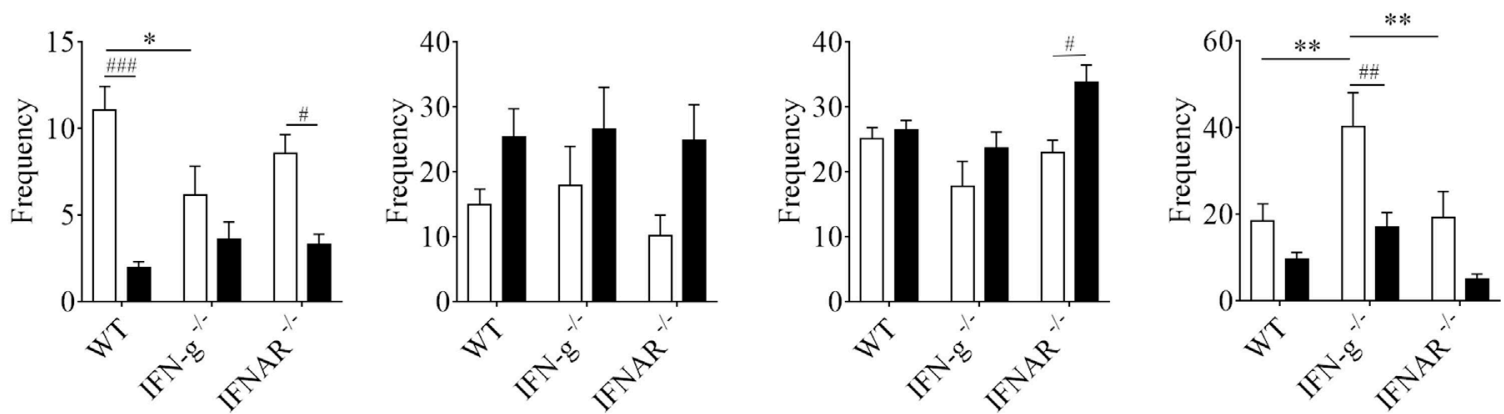

$\square$ Veh

C

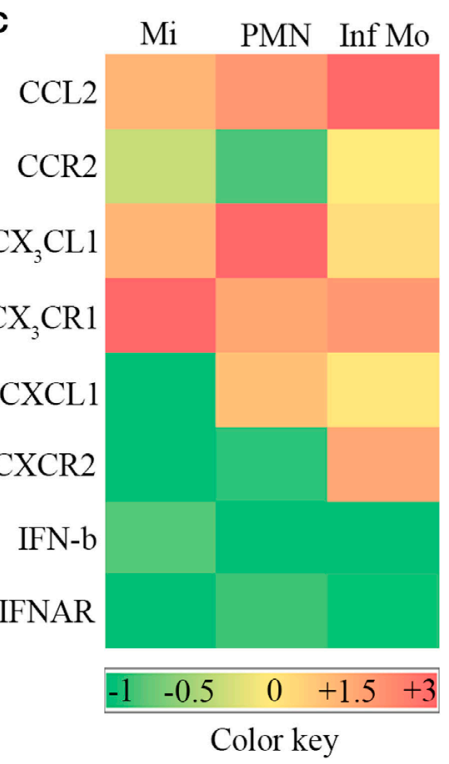

D

Gated in $\mathrm{CD} 11 \mathrm{~b}^{+} \mathrm{CD} 45^{\mathrm{hi}}$ recruited cells

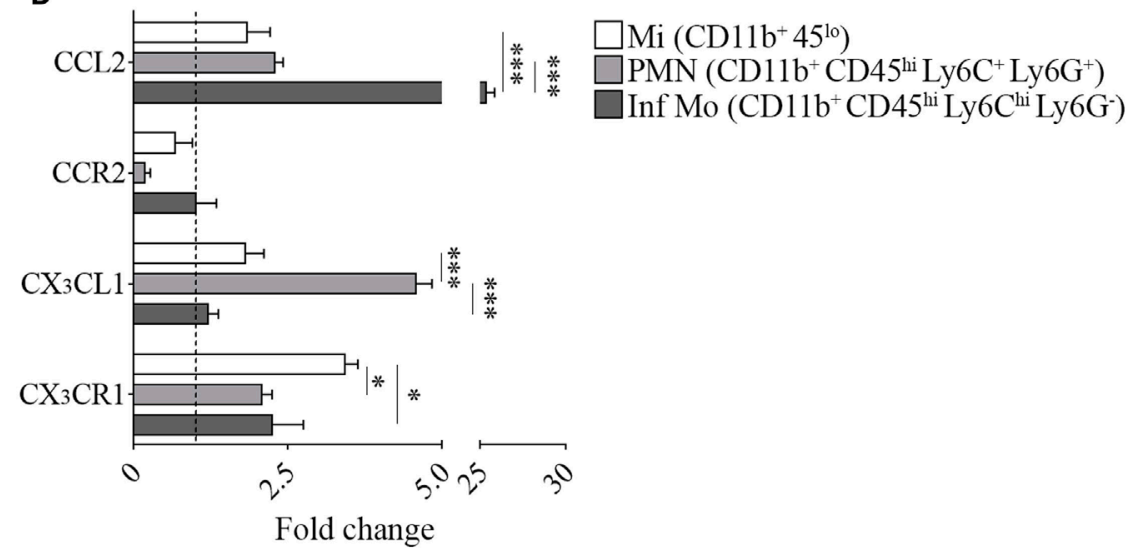

FIGURE 6 | Continued 
FIGURE 6 | Continued

Impaired recruitment of inflammatory CD11 b+ CD45 hi Ly6C ${ }^{\text {hi }}$ Ly6G $^{-}$cells in IFNAR ${ }^{-/}$endotoxemic mice. Mice were treated i.p. with either vehicle or $40 \mu$ g of lipopolysaccharide (LPS) $(1,6 \mathrm{mg} / \mathrm{kg})$ for four consecutive days to induce neuroinflammation. Twelve hours post the last injection, mice were euthanized and immune cells were isolated from whole brain homogenates and labeled for subsequent flow cytometric analysis or cell sorting. (A) Absolute number and (B) frequency of CD11 b+ CD45 microglial cells, CD11 b+/- CD45 hi recruited leukocytes, CD11b+ CD45 hi Ly6C+ Ly6G+ neutrophils, and CD11 b+ CD45 hi Ly6C hi Ly6G- inflammatory monocytes derived from wild-type (WT), IFN-g ${ }^{-/}$, and IFNAR ${ }^{-/}$mice, were assessed by flow cytometry. Results are an average of three independent experiments ( $n=3-4$ animals per group) for each knockout mice strain. (C) Heat map rendering the gene expression analysis (fold increase) by real-time PCR of CCL2, CX ${ }_{3}$ CL1, CXCL1, IFN-b and CCR2, CX ${ }_{3}$ CR1, CXCR2, IFNAR of LPS-primed CD11 b+ CD45 microglial cells, CD11b+ CD45 hi Ly6C+ $\mathrm{Ly}_{6 \mathrm{G}}{ }^{+}$neutrophils and CD11 b+ CD45 hi Ly6C ${ }^{\text {hi }}$ Ly6G $^{-}$inflammatory monocytes isolated from a pool of endotoxemic WT vs IFNAR ${ }^{-/-}$mice brains. Relative quantification $(R Q)$ was calculated based on the equation $R Q=2^{-\Delta \Delta C t}$, where Ct is the threshold cycle to detect fluorescence. Ct data were normalized to the internal standard HPRT1. Results are representative of two independent experiments ( $n=9-17$ animals per group). (D) Further comparison between CCL2, $\mathrm{CX}_{3} \mathrm{CL} 1$ and CCR2, CX ${ }_{3} \mathrm{CR} 1$ gene expression of LPS-primed CD11b+ CD45/o microglial cells, CD11b+ CD45 hi Ly6C+ Ly6G+ neutrophils, and CD11b+ CD45 hi Ly6C $^{\text {hi }}$ Ly6G $^{-}$inflammatory monocytes from WT (dashed line) vs IFNAR ${ }^{-1-}$ mice. Data are expressed as mean \pm SEM. Mi, microglial cells; PMN, neutrophils; Inf Mo, inflammatory monocytes.

$(46,47)$, inflammatory monocytes showed responsiveness in the enhancement of $\mathrm{T}$ cell proliferation. Zhu et al. (48) clearly showed that CNS isolated inflammatory monocytes could switch their function (49) from antigen presentation to T suppression depending on their activation state and therefore, their ability to produce nitric oxide. In this regard, LPS-treated inflammatory monocytes exhibited an activation threshold higher enough to differentially modulate $\mathrm{CD}^{+}(50)$ and $\mathrm{CD}^{+} \mathrm{T}$ cell subsets but not to promote $\mathrm{T}$ cell suppression. Besides, the surprisingly functional incompetence of tissue-resident microglia to favor $\mathrm{T}$ cell proliferation, which contrasts with other studies done in experimental autoimmune encephalomyelitis (51), highlights the role of peripheral inflammatory monocytes to elicit an appropriate immune response within the CNS in endotoxemic mice.

Type I IFN-mediated recruitment of inflammatory monocytes confirms the importance of these cytokines to orchestrate the trafficking of these cells $(52-55)$ to the CNS $(40,56,57)$ and reveals an unknown interaction with $\mathrm{CX}_{3} \mathrm{CL} 1$ to exert its role. Janova et al. (13) recently described an essential function for TLR4 co-receptor CD14 in microglial sensing of CNS damage $(6,10)$ and further characterized a loop by which IFN-b signaling limits CXCL1 overproduction, thereby modulating myeloid recruitment. Even though CXCL1 appear to be dispensable for neutrophils (14), this could partially explain the reason why these cells still migrate to the CNS albeit type I IFN deficiency.

Although experimental procedures to distinguish properly between microglia and monocytes in CNS impose practical limitations, the results presented here compares the phenotypic and functional features between these tissue-resident vs peripheral recruited cells in LPS-induced neuroinflammation, identifying inflammatory monocytes as key surveillants of the CNS and potential targets for immunotherapy.

\section{ETHICS STATEMENT}

All experiments were done in compliance with the procedures outlined in the "Guide for the Care and Use of Laboratory Animals" (NIH Publication No. 86-23, 1985). The experimental protocols were approved by the Institutional Animal Care and Use Committee (IACUC). Our animal facility obtained NIH animal welfare assurance (No. A5802-01, OLAW, NIH, US).

\section{AUTHOR CONTRIBUTIONS}

JPR conceived and designed the research study, performed the experiments, analyzed data, and wrote the manuscript; CB, EG, and DA performed the experiments and analyzed the data; NB performed the experiments; CRG conceived and designed the research; PI conceived and designed the research study and wrote the manuscript; all authors reviewed the manuscript before submission.

\section{ACKNOWLEDGMENTS}

The authors thank Alejandra Romero for cell culture assistance; Fabricio Navarro, Diego Luti, Carolina Florit, Victoria Blanco, and Ivanna Novotny-Núñez for animal care and Pilar Crespo and Paula Abadie for cell sorting technical support.

\section{FUNDING}

This work was supported in part by Secretaría de Ciencia y Tecnología from Universidad Nacional de Córdoba (SECyT), Agencia Nacional de Promoción Científica y Tecnológica (ANPCyT), Fondo para la Investigación Científica y Tecnológica (FONCyT), and Consejo Nacional de Investigaciones Científicas y Técnicas (CONICET).

\section{SUPPLEMENTARY MATERIAL}

The Supplementary Material for this article can be found online at http://www.frontiersin.org/article/10.3389/fimmu.2017.01666/ full\#supplementary-material.

FIGURE S1 | Gating strategy sequence applied for the flow cytometric analysis and cell sorting. Mice were treated i.p. with $40 \mu \mathrm{g}$ of lipopolysaccharide (LPS) $(1,6 \mathrm{mg} / \mathrm{kg})$ for four consecutive days to induce neuroinflammation. Twelve hours post the last injection, mice were euthanized and immune cells were isolated from whole brain homogenates and labeled for subsequent flow cytometric analysis or cell sorting. (A) FSC vs SSC, FSC-W vs FSC-H, and SSC-W vs SSC-H flow cytometry density-plots illustrating the gating analysis strategy employed to exclude cell doublets. (B) Hierarchical gate view depicting the strategy sequence adopted to assess the phenotypic features of immune cells. Representative rectangle gates were used in all cases for statistical purpose rather than for selection of a cell population. 
FIGURE S2 | Two-step intracellular staining Ctrl. Mice were treated i.p. with $40 \mu \mathrm{g}$ of lipopolysaccharide (LPS) $(1,6 \mathrm{mg} / \mathrm{kg})$ for four consecutive days to induce neuroinflammation. Twelve hours post the last injection, mice were euthanized and immune cells isolated and labeled for subsequent flow cytometric analysis. CD11b/Ly6C vs Alexa Fluor 488 flow cytometry densityplots illustrating the secondary antibody control from the intracellular labeling of $\mathrm{CCR} 2$ and $\mathrm{CX}_{3} \mathrm{CR} 1$. Representative rectangle gates were used in all cases for statistical purpose rather than for selection of a cell population.

FIGURE S3 | Weight loss comparison between wild-type (WT), IFN-g-/, and IFNAR ${ }^{-/-}$mice strains following LPS stimulation. Weight loss was assessed in WT, IFN-g ${ }^{-/-}$, and IFNAR ${ }^{-/}$mice following the i.p. administration scheme with vehicle or $40 \mu \mathrm{g}$ of lipopolysaccharide (LPS) $(1,6 \mathrm{mg} / \mathrm{kg})$ for four consecutive days to induce neuroinflammation. Results are an average of three independent experiments ( $n=3-4$ animals per group) for each knockout mice strain. Data are expressed as mean \pm SEM. Statistical significance levels were set as follows: \#\#\# if $p<0.001$ (WT-Veh, IFN-g ${ }^{-/-}$Veh, and IFNAR ${ }^{-/}$Veh vs WT-LPS, IFN-g-/- LPS,

\section{REFERENCES}

1. Ousman SS, Kubes P. Immune surveillance in the central nervous system. Nat Neurosci (2012) 15(8):1096-101. doi:10.1038/nn.3161

2. Prinz M, Priller J. The role of peripheral immune cells in the CNS in steady state and disease. Nat Neurosci (2017) 20(2):136-44. doi:10.1038/nn.4475

3. Rotta G, Edwards EW, Sangaletti S, Bennett C, Ronzoni S, Colombo MP, et al. Lipopolysaccharide or whole bacteria block the conversion of inflammatory monocytes into dendritic cells in vivo. J Exp Med (2003) 198(8):1253-63. doi:10.1084/jem.20030335

4. Cunningham C, Wilcockson DC, Campion S, Lunnon K, Perry VH. Central and systemic endotoxin challenges exacerbate the local inflammatory response and increase neuronal death during chronic neurodegeneration. J Neurosci (2005) 25(40):9275-84. doi:10.1523/JNEUROSCI.261405.2005

5. Cardona AE, Pioro EP, Sasse ME, Kostenko V, Cardona SM, Dijkstra IM, et al. Control of microglial neurotoxicity by the fractalkine receptor. Nat Neurosci (2006) 9(7):917-24. doi:10.1038/nn1715

6. Zhou H, Lapointe BM, Clark SR, Zbytnuik L, Kubes P. A requirement for microglial TLR4 in leukocyte recruitment into brain in response to lipopolysaccharide. J Immunol (2006) 177(11):8103-10. doi:10.4049/jimmunol. 177.11 .8103

7. Qin L, Wu X, Block ML, Liu Y, Breese GR, Hong JS, et al. Systemic LPS causes chronic neuroinflammation and progressive neurodegeneration. Glia (2007) 55(5):453-62. doi:10.1002/glia.20467

8. Lee JW, Lee YK, Yuk DY, Choi DY, Ban SB, Oh KW, et al. Neuroinflammation induced by lipopolysaccharide causes cognitive impairment through enhancement of beta-amyloid generation. J Neuroinflammation (2008) 5:37. doi:10.1186/1742-2094-5-37

9. Ruiz-Valdepenas L, Martinez-Orgado JA, Benito C, Millan A, Tolon RM, Romero J. Cannabidiol reduces lipopolysaccharide-induced vascular changes and inflammation in the mouse brain: an intravital microscopy study. J Neuroinflammation (2011) 8(1):5. doi:10.1186/1742-2094-8-5

10. Melief J, Koning N, Schuurman KG, Van De Garde MD, Smolders J, Hoek RM, et al. Phenotyping primary human microglia: tight regulation of LPS responsiveness. Glia (2012) 60(10):1506-17. doi:10.1002/glia.22370

11. Cunningham C. Microglia and neurodegeneration: the role of systemic inflammation. Glia (2013) 61(1):71-90. doi:10.1002/glia.22350

12. Cazareth J, Guyon A, Heurteaux C, Chabry J, Petit-Paitel A. Molecular and cellular neuroinflammatory status of mouse brain after systemic lipopolysaccharide challenge: importance of CCR2/CCL2 signaling. J Neuroinflammation (2014) 11:132. doi:10.1186/1742-2094-11-132

13. Janova H, Bottcher C, Holtman IR, Regen T, van Rossum D, Gotz A, et al. $\mathrm{CD} 14$ is a key organizer of microglial responses to CNS infection and injury. Glia (2016) 64(4):635-49. doi:10.1002/glia.22955

14. Reber LL, Gillis CM, Starkl P, Jonsson F, Sibilano R, Marichal T, et al. Neutrophil myeloperoxidase diminishes the toxic effects and mortality induced by lipopolysaccharide. J Exp Med (2017) 214(5):1249-58. doi:10.1084/ jem. 20161238 and IFNAR ${ }^{-/-}$LPS), ${ }^{* * *}$ if $p<0.001$ (WT-LPS vs IFN-g ${ }^{-/-}$LPS), a if $p<0.001$ (WT-LPS vs IFNAR ${ }^{-/-}$LPS).

FIGURE S4 | Major histocompatibility class II (MHC II) expression comparison between brain-resident CD11 b+ $C D 45^{\text {lo }}$ vs peripheral CD11 b+ CD45 hi $\mathrm{Ly}^{+} \mathrm{C}^{+}$ $\mathrm{Ly}_{6 \mathrm{G}}{ }^{+}$and $\mathrm{CD} 11 \mathrm{~b}^{+} \mathrm{CD} 45^{\text {hi }} \mathrm{Ly} \mathrm{C}^{\text {hi }}$ Ly6G- cells in LPS-treated WT, IFN-g ${ }^{-/-}$, and $\mathrm{IFNAR}^{-/-}$mice strains. Mice were treated i.p. with either vehicle or $40 \mathrm{\mu g}$ of lipopolysaccharide (LPS) $(1,6 \mathrm{mg} / \mathrm{kg})$ for four consecutive days to induce neuroinflammation. Twelve hours post the last injection, mice were euthanised and immune cells were isolated from whole brain homogenates and labelled for subsequent flow cytometric analysis. (A) Absolute number and (B) mean fluorescence intensity (MFI) of CD11 b $\mathrm{b}^{+} \mathrm{CD} 45^{10} \mathrm{MHC} \mathrm{I+}$ microglial cells, CD11 b+ $\mathrm{CD}_{4} 5^{\text {hi }} \mathrm{Ly}_{6 \mathrm{C}}+\mathrm{Ly}_{6 \mathrm{G}}+\mathrm{MHC} \mathrm{II}^{+}$neutrophils and CD11 b+ CD45 hi Ly6C ${ }^{\text {hi }}$ Ly6G- MHC

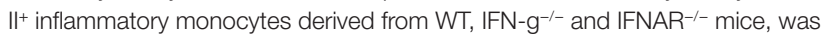
assessed by flow cytometry. Results are an average of three independent experiments ( $n=3-4$ animals per group) for each knock-out mice strain. Data are expressed as mean \pm SEM.

15. Tay TL, Mai D, Dautzenberg J, Fernandez-Klett F, Lin G, Sagar, et al. A new fate mapping system reveals context-dependent random or clonal expansion of microglia. Nat Neurosci (2017) 20(6):793-803. doi:10.1038/nn.4547

16. Nimmerjahn A, Kirchhoff F, Helmchen F. Resting microglial cells are highly dynamic surveillants of brain parenchyma in vivo. Science (2005) 308(5726):1314-8. doi:10.1126/science.1110647

17. Geissmann F, Jung S, Littman DR. Blood monocytes consist of two principal subsets with distinct migratory properties. Immunity (2003) 19(1):71-82. doi:10.1016/s1074-7613(03)00174-2

18. Segura E, Amigorena S. Inflammatory dendritic cells in mice and humans. Trends Immunol (2013) 34(9):440-5. doi:10.1016/j.it.2013.06.001

19. Mildner A, Schmidt H, Nitsche M, Merkler D, Hanisch UK, Mack M, et al. Microglia in the adult brain arise from Ly-6ChiCCR2+ monocytes only under defined host conditions. Nat Neurosci (2007) 10(12):1544-53. doi:10.1038/nn2015

20. Getts DR, Terry RL, Getts MT, Muller M, Rana S, Shrestha B, et al. Ly6c+ "inflammatory monocytes" are microglial precursors recruited in a pathogenic manner in West Nile virus encephalitis. J Exp Med (2008) 205(10): 2319-37. doi:10.1084/jem.20080421

21. Aspelund A, Antila S, Proulx ST, Karlsen TV, Karaman S, Detmar M, et al. A dural lymphatic vascular system that drains brain interstitial fluid and macromolecules. J Exp Med (2015) 212(7):991-9. doi:10.1084/jem.20142290

22. Louveau A, Smirnov I, Keyes TJ, Eccles JD, Rouhani SJ, Peske JD, et al. Structural and functional features of central nervous system lymphatic vessels. Nature (2015) 523(7560):337-41. doi:10.1038/nature14432

23. Deczkowska A, Baruch K, Schwartz M. Type I/II interferon balance in the regulation of brain physiology and pathology. Trends Immunol (2016) 37(3):181-92. doi:10.1016/j.it.2016.01.006

24. Ransohoff RM, Engelhardt B. The anatomical and cellular basis of immune surveillance in the central nervous system. Nat Rev Immunol (2012) 12(9): 623-35. doi:10.1038/nri3265

25. Peelaerts W, Bousset L, Van der Perren A, Moskalyuk A, Pulizzi R, Giugliano M, et al. alpha-Synuclein strains cause distinct synucleinopathies after local and systemic administration. Nature (2015) 522(7556):340-4. doi:10.1038/nature14547

26. Perry VH, Newman TA, Cunningham C. The impact of systemic infection on the progression of neurodegenerative disease. Nat Rev Neurosci (2003) 4(2):103-12. doi:10.1038/nrn 1032

27. Yamasaki R, Lu H, Butovsky O, Ohno N, Rietsch AM, Cialic R, et al. Differential roles of microglia and monocytes in the inflamed central nervous system. J Exp Med (2014) 211(8):1533-49. doi:10.1084/jem. 20132477

28. Ritzel RM, Patel AR, Grenier JM, Crapser J, Verma R, Jellison ER, et al. Functional differences between microglia and monocytes after ischemic stroke. J Neuroinflammation (2015) 12:106. doi:10.1186/s12974-015-0329-1

29. Shi C, Pamer EG. Monocyte recruitment during infection and inflammation. Nat Rev Immunol (2011) 11(11):762-74. doi:10.1038/nri3070

30. Greter M, Helft J, Chow A, Hashimoto D, Mortha A, Agudo-Cantero J, et al. GM-CSF controls nonlymphoid tissue dendritic cell homeostasis but is 
dispensable for the differentiation of inflammatory dendritic cells. Immunity (2012) 36(6):1031-46. doi:10.1016/j.immuni.2012.03.027

31. Ji Q, Castelli L, Goverman JM. MHC class I-restricted myelin epitopes are cross-presented by Tip-DCs that promote determinant spreading to CD8(+) T cells. Nat Immunol (2013) 14(3):254-61. doi:10.1038/ni.2513

32. Ransohoff RM, Kivisakk P, Kidd G. Three or more routes for leukocyte migration into the central nervous system. Nat Rev Immunol (2003) 3(7):569-81. doi:10.1038/nri1130

33. Shechter R, Miller O, Yovel G, Rosenzweig N, London A, Ruckh J, et al. Recruitment of beneficial M2 macrophages to injured spinal cord is orchestrated by remote brain choroid plexus. Immunity (2013) 38(3):555-69. doi:10.1016/j.immuni.2013.02.012

34. Baruch K, Deczkowska A, David E, Castellano JM, Miller O, Kertser A, et al. Aging. Aging-induced type I interferon response at the choroid plexus negatively affects brain function. Science (2014) 346(6205):89-93. doi:10.1126/ science. 1252945

35. Baruch K, Kertser A, Porat Z, Schwartz M. Cerebral nitric oxide represses choroid plexus NFkappaB-dependent gateway activity for leukocyte trafficking. EMBO J (2015) 34(13):1816-28. doi:10.15252/embj.201591468

36. Dickens AM, Tovar YRLB, Yoo SW, Trout AL, Bae M, Kanmogne M, et al. Astrocyte-shed extracellular vesicles regulate the peripheral leukocyte response to inflammatory brain lesions. Sci Signal (2017) 10(473):eaai7696. doi:10.1126/scisignal.aai7696

37. Dal-Secco D, Wang J, Zeng Z, Kolaczkowska E, Wong CH, Petri B, et al. A dynamic spectrum of monocytes arising from the in situ reprogramming of CCR2+ monocytes at a site of sterile injury. J Exp Med (2015) 212(4):447-56. doi:10.1084/jem.20141539

38. Ransohoff RM. Chemokines and chemokine receptors: standing at the crossroads of immunobiology and neurobiology. Immunity (2009) 31(5): 711-21. doi:10.1016/j.immuni.2009.09.010

39. Prinz M, Priller J. Tickets to the brain: role of CCR2 and CX3CR1 in myeloid cell entry in the CNS. J Neuroimmunol (2010) 224(1-2):80-4. doi:10.1016/j. jneuroim.2010.05.015

40. D'Mello C, Le T, Swain MG. Cerebral microglia recruit monocytes into the brain in response to tumor necrosis factoralpha signaling during peripheral organ inflammation. J Neurosci (2009) 29(7):2089-102. doi:10.1523/ JNEUROSCI.3567-08.2009

41. Saederup N, Cardona AE, Croft K, Mizutani M, Cotleur AC, Tsou CL, et al. Selective chemokine receptor usage by central nervous system myeloid cells in CCR2-red fluorescent protein knock-in mice. PLoS One (2010) 5(10):e13693. doi:10.1371/journal.pone.0013693

42. Hammond MD, Taylor RA, Mullen MT, Ai Y, Aguila HL, Mack M, et al. CCR2+ Ly6C(hi) inflammatory monocyte recruitment exacerbates acute disability following intracerebral hemorrhage. J Neurosci (2014) 34(11): 3901-9. doi:10.1523/JNEUROSCI.4070-13.2014

43. Ransohoff RM, Cardona AE. The myeloid cells of the central nervous system parenchyma. Nature (2010) 468(7321):253-62. doi:10.1038/nature09615

44. Limatola C, Ransohoff RM. Modulating neurotoxicity through CX3CL1/ CX3CR1 signaling. Front Cell Neurosci (2014) 8:229. doi:10.3389/ fncel.2014.00229

45. Braun M, Vaibhav K, Saad N, Fatima S, Brann DW, Vender JR, et al. Activation of myeloid TLR4 mediates T lymphocyte polarization after traumatic brain injury. J Immunol (2017) 198(9):3615-26. doi:10.4049/jimmunol.1601948

46. Gabrilovich DI, Nagaraj S. Myeloid-derived suppressor cells as regulators of the immune system. Nat Rev Immunol (2009) 9(3):162-74. doi:10.1038/nri2506
47. Condamine T, Gabrilovich DI. Molecular mechanisms regulating myeloidderived suppressor cell differentiation and function. Trends Immunol (2011) 32(1):19-25. doi:10.1016/j.it.2010.10.002

48. Zhu B, Kennedy JK, Wang Y, Sandoval-Garcia C, Cao L, Xiao S, et al. Plasticity of Ly-6C(hi) myeloid cells in T cell regulation. J Immunol (2011) 187(5):2418-32. doi:10.4049/jimmunol.1100403

49. Shalova IN, Lim JY, Chittezhath M, Zinkernagel AS, Beasley F, HernandezJimenez E, et al. Human monocytes undergo functional re-programming during sepsis mediated by hypoxia-inducible factor-1alpha. Immunity (2015) 42(3):484-98. doi:10.1016/j.immuni.2015.02.001

50. Waschbisch A, Schroder S, Schraudner D, Sammet L, Weksler B, Melms A, et al. Pivotal role for $\mathrm{CD} 16+$ monocytes in immune surveillance of the central nervous system. J Immunol (2016) 196(4):1558-67. doi:10.4049/jimmunol. 1501960

51. Wlodarczyk A, Lobner M, Cedile O, Owens T. Comparison of microglia and infiltrating $\mathrm{CD} 11 \mathrm{c}(+)$ cells as antigen presenting cells for T cell proliferation and cytokine response. J Neuroinflammation (2014) 11:57. doi:10.1186/ 1742-2094-11-57

52. Jia T, Leiner I, Dorothee G, Brandl K, Pamer EG. MyD88 and Type I interferon receptor-mediated chemokine induction and monocyte recruitment during Listeria monocytogenes infection. J Immunol (2009) 183(2):1271-8. doi:10.4049/jimmunol.0900460

53. Uyangaa E, Kim JH, Patil AM, Choi JY, Kim SB, Eo SK. Distinct upstream role of type I IFN signaling in hematopoietic stem cell-derived and epithelial resident cells for concerted recruitment of Ly-6Chi monocytes and NK cells via CCL2-CCL3 cascade. PLoS Pathog (2015) 11(11):e1005256. doi:10.1371/journal.ppat.1005256

54. Sammicheli S, Kuka M, Di Lucia P, de Oya NJ, De Giovanni M, Fioravanti J, et al. Inflammatory monocytes hinder antiviral B cell responses. Sci Immunol (2016) 1(4):eaah6789. doi:10.1126/sciimmunol.aah6789

55. Lee AJ, Chen B, Chew MV, Barra NG, Shenouda MM, Nham T, et al. Inflammatory monocytes require type I interferon receptor signaling to activate NK cells via IL-18 during a mucosal viral infection. J Exp Med (2017) 214(4):1153-67. doi:10.1084/jem.20160880

56. Prinz M, Schmidt H, Mildner A, Knobeloch KP, Hanisch UK, Raasch J, et al. Distinct and nonredundant in vivo functions of IFNAR on myeloid cells limit autoimmunity in the central nervous system. Immunity (2008) 28(5):675-86. doi:10.1016/j.immuni.2008.03.011

57. Wolf Y, Shemer A, Polonsky M, Gross M, Mildner A, Yona S, et al. Autonomous TNF is critical for in vivo monocyte survival in steady state and inflammation. JExp Med (2017) 214(4):905-17. doi:10.1084/jem. 20160499

Conflict of Interest Statement: The authors declare that the research was conducted in the absence of any commercial or financial relationships that could be construed as a potential conflict of interest.

Copyright $\odot 2017$ Peralta Ramos, Bussi, Gaviglio, Arroyo, Baez, Rodriguez-Galan and Iribarren. This is an open-access article distributed under the terms of the Creative Commons Attribution License (CC BY). The use, distribution or reproduction in other forums is permitted, provided the original author(s) or licensor are credited and that the original publication in this journal is cited, in accordance with accepted academic practice. No use, distribution or reproduction is permitted which does not comply with these terms. 